\title{
Analysis of co-located MODIS and CALIPSO observations near clouds
}

\author{
T. Várnai ${ }^{1}$ and A. Marshak ${ }^{2}$ \\ ${ }^{1}$ University of Maryland Baltimore County, Joint Center for Earth System Technology, USA \\ ${ }^{2}$ NASA Goddard Space Flight Center, Climate and Radiation Laboratory, USA \\ Correspondence to: T. Várnai (tamas.varnai@ nasa.gov)
}

Received: 8 October 2011 - Published in Atmos. Meas. Tech. Discuss.: 14 November 2011

Revised: 6 February 2012 - Accepted: 7 February 2012 - Published: 17 February 2012

\begin{abstract}
This paper aims at helping synergistic studies in combining data from different satellites for gaining new insights into two critical yet poorly understood aspects of anthropogenic climate change, aerosol-cloud interactions and aerosol radiative effects. In particular, the paper examines the way cloud information from the MODIS (MODerate resolution Imaging Spectroradiometer) imager can refine our perceptions based on CALIOP (Cloud-Aerosol Lidar with Orthogonal Polarization) lidar measurements about the systematic aerosol changes that occur near clouds.

The statistical analysis of a yearlong dataset of colocated global maritime observations from the Aqua and CALIPSO (Cloud-Aerosol Lidar and Infrared Pathfinder Satellite Observation) satellites reveals that MODIS's multispectral imaging ability can greatly help the interpretation of CALIOP observations. The results show that imagers on Aqua and CALIPSO yield very similar pictures, and that the discrepancies - due mainly to wind drift and differences in view angle - do not significantly hinder aerosol measurements near clouds. By detecting clouds outside the CALIOP track, MODIS reveals that clouds are usually closer to clear areas than CALIOP data alone would suggest. The paper finds statistical relationships between the distances to clouds in MODIS and CALIOP data, and proposes a rescaling approach to statistically account for the impact of clouds outside the CALIOP track even when MODIS cannot reliably detect low clouds, for example at night or over sea ice. Finally, the results show that the typical distance to clouds depends on both cloud coverage and cloud type, and accordingly varies with location and season. In maritime areas perceived cloud free, the global median distance to clouds below $3 \mathrm{~km}$ altitude is in the $4-5 \mathrm{~km}$ range.
\end{abstract}

\section{Introduction}

Aerosol measurements near clouds play an important role in studying two critical yet poorly understood aspects of anthropogenic climate change, aerosol-cloud interactions and aerosol radiative effects (e.g. Loeb and Schuster, 2008). Such measurements indicate that clouds are surrounded by a wide transition zone, in which aerosol optical properties and particle size change systematically (e.g. Koren et al., 2007; Su et al., 2008; Chiu et al., 2009; Redemann et al., 2009; Twohy et al., 2009; Várnai and Marshak, 2011; Bar-Or et al., 2011). Several factors can alter particle populations in the vicinity of clouds, for example aerosols swelling in the humid air surrounding clouds (e.g. Twohy et al., 2009; Jeong and Li, 2010), aerosol particles merging when cloud droplets merge through coagulation and then evaporate (e.g. Kerkweg et al., 2003; Tackett and Di Girolamo, 2009), a few large particles lingering around after a cloud dissipates (e.g. Xue et al., 2008), and even a few droplets appearing before stable clouds could form (e.g. Koren et al., 2009).

While satellites offer excellent opportunities for aerosol studies, satellite measurements of aerosols are particularly challenging near clouds. For example, even the separation of cloudy and cloud-free areas is often ambiguous, as very thin or small clouds can appear similar to thick aerosols in satellite data (e.g. Charlson et al., 2007; Koren et al., 2008; Redemann et al., 2009), and both aerosol and cloud particles can be present in the atmospheric column or volume we observe (Liu et al., 2009). This leads to difficulties in the correct interpretation of satellite measurements and, as a result, to bigger uncertainties in remote sensing retrievals.

The combination of remote sensing uncertainties and systematic aerosol changes near clouds creates a dilemma for researchers (Várnai and Marshak, 2011): on one hand, excluding the transition zone in order to avoid its remote sensing uncertainties and misinterpretation can create a bias toward low aerosol optical depths thus weaker radiative effects 
calculated from these optical depths. On the other hand, including the transition zone despite the remote sensing uncertainties can create a bias toward too high aerosol optical depths and stronger radiative effects. Improving our ability to measure aerosols near clouds and to better understand the impact of remote sensing uncertainties can help resolve this dilemma, and yield more precise information on aerosolcloud interactions and aerosol radiative effects.

This paper explores issues related to combining data from two different satellites with the goal of obtaining more detailed information on aerosols near clouds. Combining data from various instruments allows one to take advantage of the active and passive instruments' capabilities and limitations complementing each other (e.g. vertical information but larger noise for a lidar, and spectral and cross-track information but complications due to 3-D radiative processes for passive imagers). Specifically, the paper examines various possibilities and concerns in combining data from the CALIOP (Cloud-Aerosol Lidar with Orthogonal Polarization) lidar on the CALIPSO (Cloud-Aerosol Lidar and Infrared Pathfinder Satellite Observation) satellite with data from the MODIS (Moderate Resolution Imaging Spectroradiometer) imager on the Aqua satellite. Data from the WFC (Wide Field Camera) imager on the CALIPSO satellite is also used in exploring the combination of MODIS and CALIOP data.

\section{Data}

This study analyzes a yearlong (November 2006October 2007) global dataset of daytime satellite data over all oceans free of sea ice between latitudes $60^{\circ}$ South and $60^{\circ}$ North.

The study uses the operational $1 \mathrm{~km}$-resolution CALIOP cloud mask and cloud top altitude products (Vaughan et al., 2009; Winker et al., 2009), and also attenuated lidar backscatter (called "backscatter" throughout this paper for brevity) profiles at both $532 \mathrm{~nm}$ and $1064 \mathrm{~nm}$ wavelengths, degraded from $333 \mathrm{~m}$ to $1 \mathrm{~km}$ resolution. We note that CALIOP also provides a $5 \mathrm{~km}$-resolution cloud mask, which is especially effective in detecting thin cirrus clouds. Since this advantage is less critical in our study (as discussed in Sect. 3, we examine the vicinity of low-level clouds), the $1 \mathrm{~km}$ mask is used, which (i) accounts for small cloud-free gaps in cumulus fields, (ii) provides the distance to nearest cloud at a higher resolution (iii) makes comparisons to the $1 \mathrm{~km}$-resolution MODIS cloud mask easier. The analysis also uses $61 \mathrm{~km}$ wide swaths of $1 \mathrm{~km}$-resolution WFC images of $0.65 \mu \mathrm{m}$ solar reflectance. These images are registered to the lidar measurements such that they extend $30 \mathrm{~km}$ away on each side of the single line that is observed by the lidar along the satellite orbit.

In order to reduce data volume, we obtained MODIS data for $201 \mathrm{~km}$ wide swaths from NASA's A-train data depot at http://disc.sci.gsfc.nasa.gov/atdd/data-holdings. MODIS products were registered to WFC images by identifying the MODIS pixel with the closest geographical coordinates to each WFC pixel. The study uses the MODIS cloud mask (Ackerman et al., 1998; Frey et al., 2008) and $0.65 \mu \mathrm{m}$ solar reflectances provided at $1 \mathrm{~km}$ resolution, and also cloud top pressures provided at $5 \mathrm{~km}$ resolution (Menzel et al., 2008).

\section{Results}

While combining data from different satellites offers new possibilities, it also poses new challenges. One such challenge is that since CALIPSO flies slightly behind Aqua, CALIOP sees the same scene $72 \mathrm{~s}$ later than MODIS. This implies that even if MODIS encounters a cloud at a given spot, the cloud drifting with the wind may move away by the time CALIOP arrives, and so solar reflectances for the cloud may be combined with lidar returns from a clear sky column. Naturally, this could cause data interpretation errors, for example overestimations of clear-sky MODIS solar reflectances near clouds when using a CALIOP cloud mask. We note that such errors can be further heightened by cloud formation or evaporation during the $72 \mathrm{~s}$ between satellite overpasses, especially in the case of small cloud fragments that are quite common in the transition zone (Koren et al., 2008).

The problem of drifting clouds can be examined with the help of the WFC imager on the CALIPSO satellite, since comparisons of $0.65 \mu \mathrm{m}$ images by WFC and MODIS can reveal cloud movements between the two satellite overpasses (Fig. 1). We estimate the impact on near-cloud reflectances by dividing the center portion of WFC imagery to $51 \mathrm{~km}$ by $51 \mathrm{~km}$ segments, and then testing what shifting of the geographically co-registered images can maximize the covariance of WFC and MODIS pixel values (using $51 \mathrm{~km}$ by $51 \mathrm{~km}$ segments that extend $25 \mathrm{~km}$ away on each side of the CALIOP track allows us to detect displacements up to $5 \mathrm{~km}$ in any direction within the $61 \mathrm{~km}$ wide available dataset). The results indicate that while clouds can certainly drift large distances when the wind is strong, this occurs mostly for high clouds such as those in Fig. 1. This study, however, focuses on clouds below $3 \mathrm{~km}$, and we found that the drift exceeds $1 \mathrm{~km}$ for less than $10 \%$ of scenes containing only clouds below $3 \mathrm{~km}$. In such scenes median MODIS reflectances plotted against the distance to the nearest cloud detected by CALIOP are very similar regardless whether or not MODIS images are shifted to maximize their covariance with WFC images. Similarly, median CALIOP backscatters plotted as a function of distance to clouds detected by MODIS are almost identical with or without wind shift correction. Wind shift makes significant differences only for the first distance bin, i.e. clear areas $1 \mathrm{~km}$ away from clouds.

Though wind shifts and cloud development during the $72 \mathrm{~s}$ between the CALIPSO and Aqua overpasses can cause random differences between WFC and MODIS images, WFC 


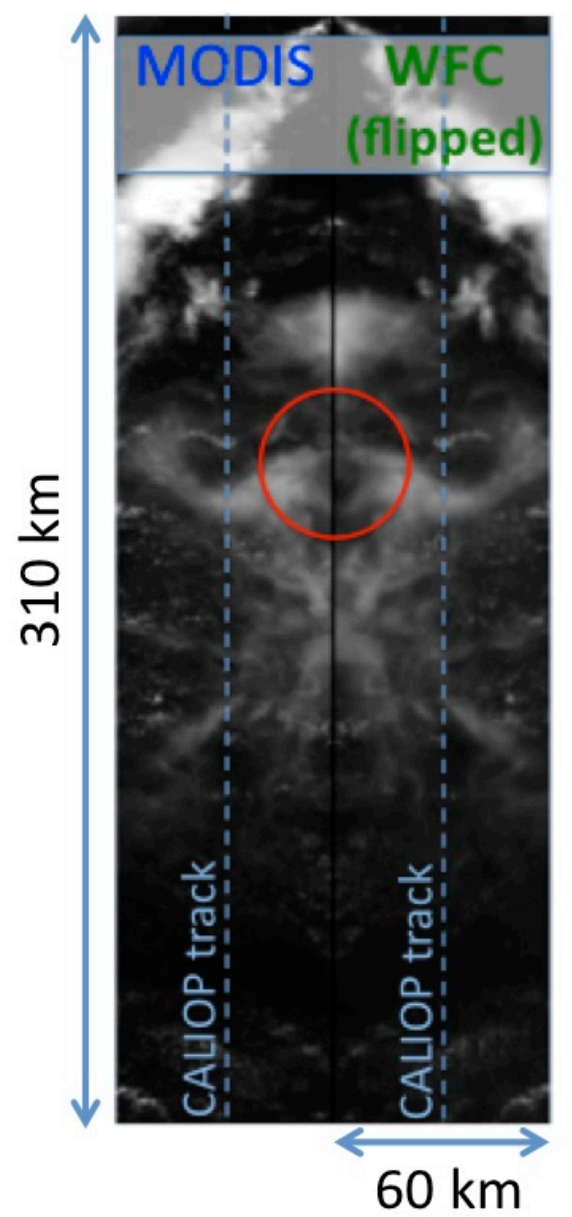

Fig. 1. A sample scene of MODIS and WFC $0.65 \mu \mathrm{m}$ reflectances. As the WFC image is flipped, the full image should be symmetric if clouds did not change between the CALIPSO and Aqua overpasses. The asymmetry highlighted by a circle illustrates clouds drifting with the wind.

and MODIS reflectances can be expected to be very similar statistically. To test this, Fig. 2 compares WFC and MODIS reflectances at the first, second, third, ..., 99th percentiles of the WFC and MODIS reflectance histograms, respectively. The figure shows that WFC and MODIS reflectances tend to be very similar, although the inset reveals that dark pixel reflectances are slightly higher for WFC than for MODIS, whereas bright pixel reflectances are slightly lower for WFC than for MODIS. These differences likely come from two main factors. First, while WFC sees the lidar footprint at nadir, MODIS sees it at a viewing zenith angle ranging from $5^{\circ}$ to $20^{\circ}$, as Aqua flies slightly off to the side and not exactly in front of CALIPSO. Such view angle differences can create systematic reflectance differences for anisotropic reflectors such as clear oceans. Second, WFC calibration uncertainties can also play a role in WFC-MODIS reflectance differences. We note that while mean reflectances are similar for WFC

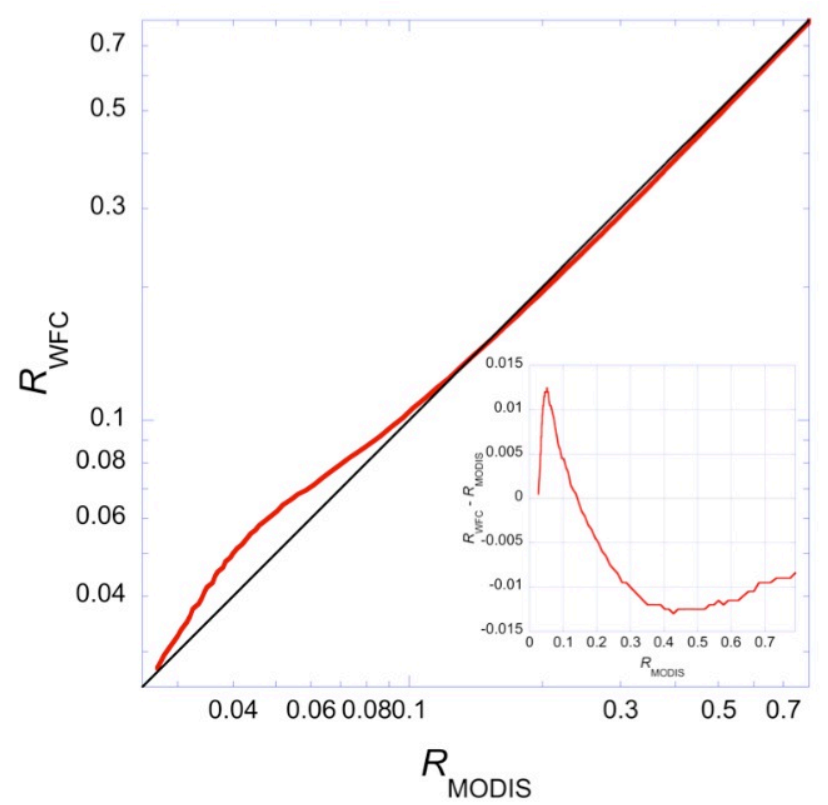

Fig. 2. Comparison of WFC and MODIS $0.65 \mu \mathrm{m}$ reflectances at the first, second, third, ..., 99th percentiles of the overall WFC and MODIS reflectance histograms. Inset: difference between WFC and MODIS reflectances at each percentile bin, plotted on a linear scale.

and MODIS, local standard deviations of 9 reflectance values within $3 \mathrm{~km}$ by $3 \mathrm{~km}$ areas is roughly $20 \%$ smaller for WFC than for MODIS images. Because the MODIS observational noise is much less than $20 \%$, this difference likely comes from a smoothing effect that can arise if WFC has a wider instantaneous field-of-view (or point spread function) than MODIS. This hypothesis is also consistent with the result that $0.65 \mu \mathrm{m}$ reflectances exhibit larger increases near clouds in WFC than in MODIS images (not shown).

One key benefit from adding MODIS data to CALIOP observations is that while CALIOP can detect clouds along a single line tracking the satellite orbit, MODIS can also detect clouds that lie off to the side from this line. Therefore it is important to examine how near-cloud behaviors change if, instead of using the CALIOP cloud mask as earlier CALIOP studies did (Tackett and Di Girolamo, 2009; Várnai and Marshak, 2011; Yang et al., 2011), we use the MODIS cloud mask. Figure 3 compares CALIOP lidar backscatter enhancements in the vicinity of clouds for three cloud masks: CALIOP mask searching for clouds along a single (1-D) line, MODIS mask searching for clouds along the same (1-D) line, and MODIS mask searching for clouds throughout the (2-D) MODIS images.

Because most near-cloud enhancements of CALIOP backscatter occur at low altitudes (Várnai and Marshak, 2011), the figure shows CALIOP backscatters integrated from $30 \mathrm{~m}$ to $3 \mathrm{~km}$ altitude. The displayed median values 


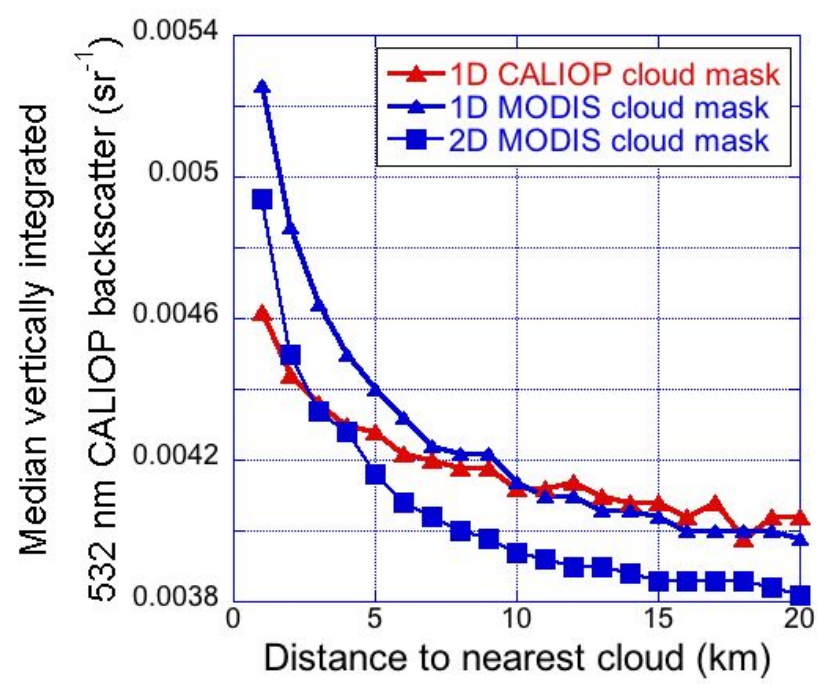

Fig. 3. Median of CALIOP $532 \mathrm{~nm}$ backscatters integrated up to $3 \mathrm{~km}$ altitude near clouds whose top is below $3 \mathrm{~km}$, for three different cloud masks (CM): CALIOP CM (red triangles), MODIS $\mathrm{CM}$ along a single line (blue triangles), and MODIS CM (blue squares). Plot is for winter (December 2006-February 2007) in the $30^{\circ}-60^{\circ}$ North latitude band. The number of used lidar profiles is in the 50000-150 000 range near clouds, but decreases to about 13000 for the bin $20 \mathrm{~km}$ away from clouds.

are obtained by first vertically integrating backscatter values for each $1 \mathrm{~km}$-size column, and then determining the 50th percentile value of all columns that lie within a certain distance bin. Since low clouds are likely to impact this altitude range the most, distance to nearby clouds in this and subsequent figures means distance to clouds below $3 \mathrm{~km}$ when using CALIOP, and distance to clouds with cloud top pressure exceeding $700 \mathrm{hPa}$ when using MODIS data (e.g. for clouds outside the CALIOP lidar track). We note that since high clouds are unlikely to influence low-altitude lidar returns from nearby cloud-free columns, the analysis considers clear-sky columns even if high clouds occur nearby, but the distance to cloud is always calculated as the distance to the nearest low cloud.

The figure shows that, at least for the first $5 \mathrm{~km}$, the MODIS 1-D mask yields higher backscatter near clouds than the CALIOP cloud mask does. This likely comes from two reasons associated with the MODIS cloud mask being less sensitive and missing some of the thin clouds identified by CALIOP (Eguchi and Yokota, 2008). First, borderline cases with relatively high particle concentrations (and hence high lidar backscatter) may be included into the clear-sky population only when using the MODIS cloud mask, since the more conservative CALIOP mask may classify these cases as clouds. For example, as MODIS and CALIOP define clouds differently, the more conservative CALIOP cloud mask may classify as cloud even some of the harder-to-detect cloudy cases mentioned in Koren et al. (2009), such as a few large particles lingering around even after the bulk of a cloud dissipates. Second, missing the thinnest clouds means that clear areas appearing next to clouds in the MODIS mask are next to relatively thick clouds, and these thicker clouds may have a stronger impact on their surroundings than the thin clouds identified only by CALIOP.

The figure also shows that the backscatter curve moves to the left (and hence lower) if we use the 2-D MODIS cloud mask instead of the 1-D one. This occurs because whenever the closest cloud lies outside the CALIOP track, 1-D searches need to go farther to find a cloud than 2-D searches do. For example, Fig. 3 shows that median backscatter reaches $0.0042 \mathrm{sr}^{-1}$ at a distance of $d_{2 \mathrm{D}}=4.5 \mathrm{~km}$ for the 2-D mask, but only at $d_{1 \mathrm{D}}=9 \mathrm{~km}$ for the 1 -D MODIS cloud mask. The 2-D curve being below the 1-D curve even at $20 \mathrm{~km}$ is likely a sign that backscatter keeps dropping in the increasingly dry air even past $20 \mathrm{~km}$ away from clouds (as in Koren et al., 2007 and Bar-Or et al., 2011), since pixels that are $20 \mathrm{~km}$ away from clouds in the 2-D mask are often even farther from the clouds found by the 1-D MODIS cloud mask that searches only along the CALIPSO track.

Finally, let us mention that the MODIS curves in Fig. 3 are based only on clear pixels labeled "confident clear" by the MODIS cloud mask, and that including "probably clear" pixels as well makes near-cloud enhancements stronger. Overall, Fig. 3 shows that while the details of near-cloud enhancements depend on the cloud mask used, their basic behavior does not change by considering off-track clouds. As a result, the transition zone surrounding clouds is likely at least as wide and pronounced as it was discussed in earlier papers considering CALIOP data only (Tackett and Di Girolamo, 2009; Várnai and Marshak, 2011; Yang et al., 2012).

The main reason for the difference between the 1-D and 2-D MODIS curves in Fig. 3 - that is, the relationship between clear areas' distance to the nearest cloud using 1-D and 2-D cloud masks - is explored quantitatively in Fig. 4a. This figure was created by selecting various color ratio values in a plot similar to Fig. 3 that displays near-cloud enhancements in color ratio rather than backscatter, and then comparing the $d_{1 \mathrm{D}}$ and $d_{2 \mathrm{D}}$ distances at which these color ratio values are attained (the color ratio, the ratio of lidar backscatters at $1064 \mathrm{~nm}$ and $532 \mathrm{~nm}$, is closely related to particle size and increases near clouds much like $532 \mathrm{~nm}$ backscatter does; Tackett and Di Girolamo, 2009; Várnai and Marshak, 2011). The horizontal and vertical positions of each dot in Fig. 4a are determined by the $d_{1 \mathrm{D}}$ and $d_{2 \mathrm{D}}$ distances for each selected color ratio value. The red and blue dots use $d_{1 \mathrm{D}}$ values from the MODIS and CALIOP cloud masks, respectively $\left(d_{2 \mathrm{D}}\right.$ is always obtained from MODIS). We note that using backscatter values rather than color ratio, or even examining the histograms of $d_{1 \mathrm{D}}$ and $d_{2 \mathrm{D}}$ directly for the red curve yield nearly identical results, with the slope of linear fits being 0.584 and 0.591 instead of 0.577 .

The slope of the red line in Fig. $4 \mathrm{a}$ is determined by the spatial scaling in clouds, which is closely related to the 

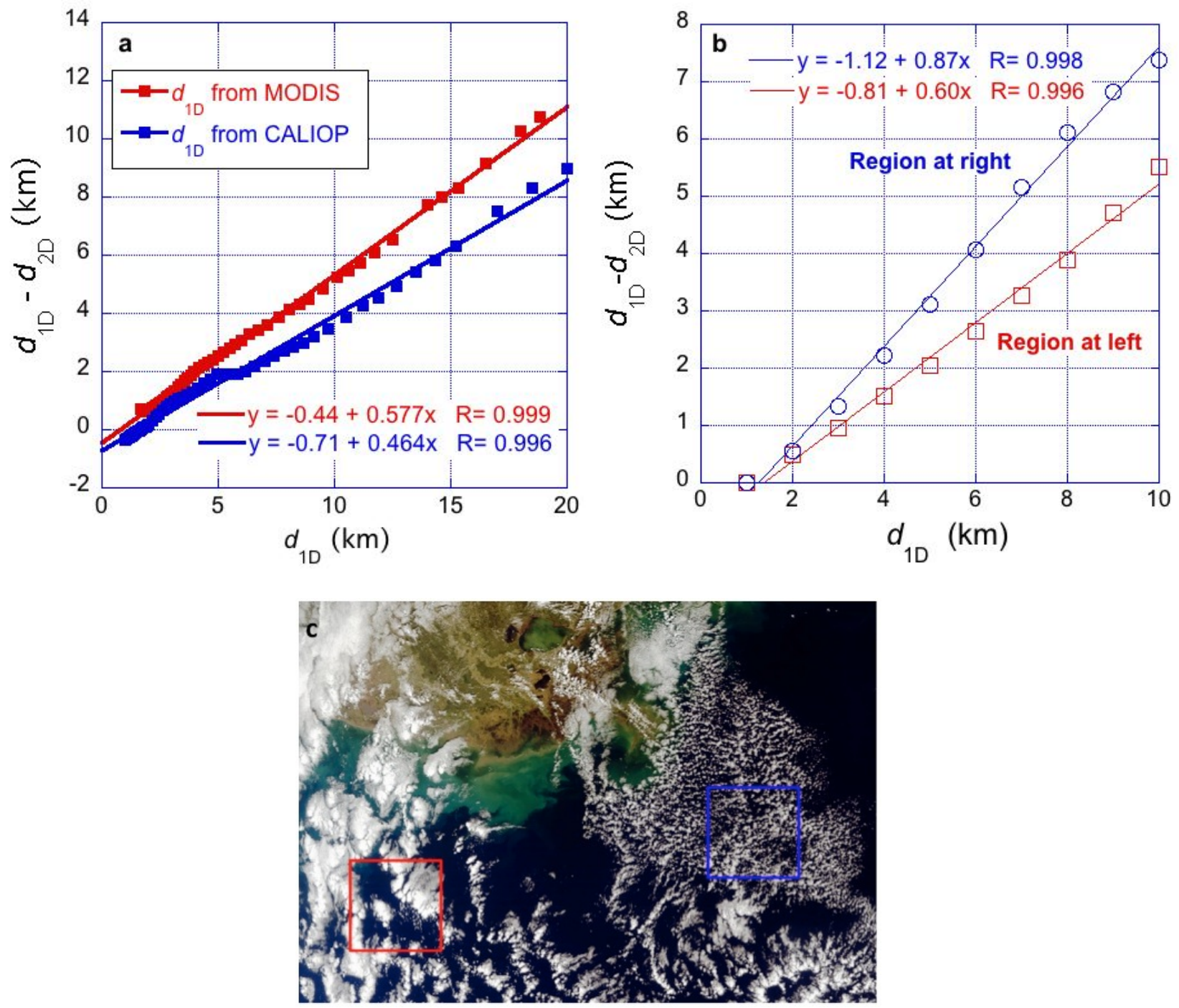

Fig. 4. (a) Relationship between clear areas' distance to the nearest clouds in 1-D and 2-D searches for clouds, based on the yearlong global dataset. (b) Same relationship for the two sample areas in (c), with the difference that $d_{1 \mathrm{D}}$ and $d_{2 \mathrm{D}}$ are obtained directly from the 2-D MODIS cloud mask (without considering lidar color ratios as in a). For each $d_{1 \mathrm{D}}$ bin, median values of $d_{1 \mathrm{D}}-d_{2 \mathrm{D}}$ are plotted. (c) MODIS image of the Mississippi delta, with the two $100 \mathrm{~km}$ by $100 \mathrm{~km}$ size sample areas highlighted. The image was taken by the MODIS instrument on the Terra satellite on 22 November 2003, at 16:40 UTC.

spatial autocorrelation of cloud fields. To illustrate this we use calculations for artificial broken cloud fields generated by a 2-D stochastic cloud model based on fractional Brownian motion (e.g. Barker and Davies, 1992; Davis et al., 1996). At one extreme, the slope is close to 1 for white noise fields because, lacking any spatial correlations, $d_{2 \mathrm{D}}$ is largely independent from $d_{1 \mathrm{D}}$ (the only connection being $d_{2 \mathrm{D}} \leq d_{1 \mathrm{D}}$ ), and hence the difference between $d_{1 \mathrm{D}}$ and $d_{2 \mathrm{D}}$ is determined by $d_{1 \mathrm{D}}$ itself. At the other extreme, for cloud fields with variability only at the very largest scales, the slope is just under $1 / 3$. This limit may be conceptually understood by considering that if large-scale variability dominates, the nearest cloud can be assumed to have a straight boundary. Therefore $d_{2 \mathrm{D}}=d_{1 \mathrm{D}} \cos \varphi$, where $\varphi$ is the angle between the CALIOP track and the line to the cloud's closest point. Simple geometry then says that the slope $s$ of the linear fit relating $d_{1 \mathrm{D}}-d_{2 \mathrm{D}}$ to $d_{1 \mathrm{D}}$ can be approximated as

$s=\frac{d_{1 \mathrm{D}}-d_{2 \mathrm{D}}}{d_{1 \mathrm{D}}}=1-\frac{d_{2 \mathrm{D}}}{d_{1 \mathrm{D}}}=1-\cos \varphi$,

which is close to 0.3 for $\varphi=45^{\circ}$.

The impact of scaling is illustrated in Fig. 4b, which compares the slopes for the two sample areas highlighted in Fig. 4c. In particular, panel $\mathrm{b}$ shows that the slope is significantly steeper ( 0.87 vs. 0.60$)$ for the right side area dominated by small-scale variability, than for the left side area 


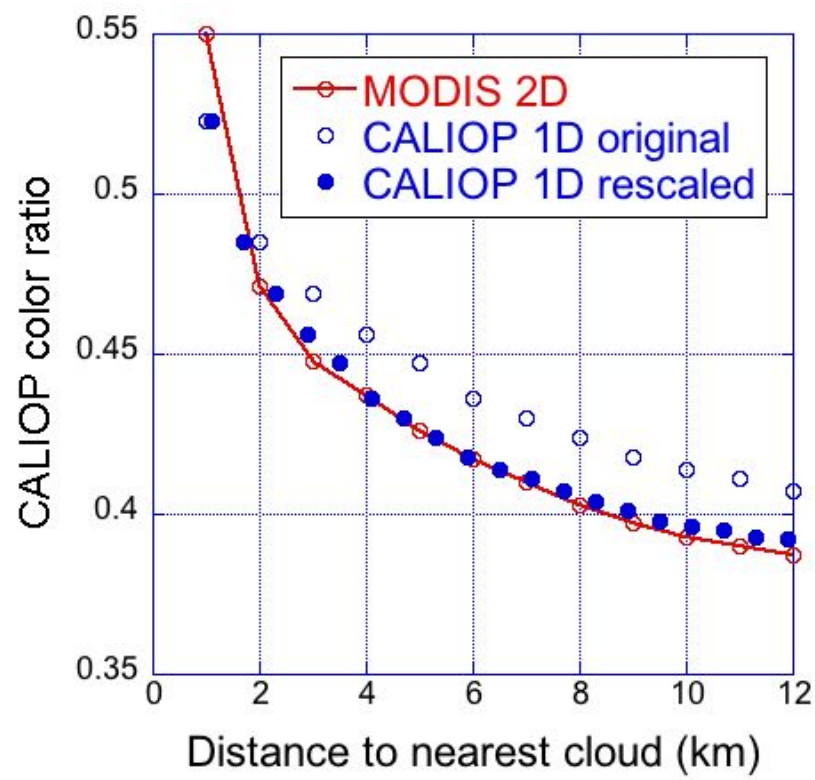

Fig. 5. Median CALIOP color ratio (integrated up to $3 \mathrm{~km}$ altitude) near clouds detected by the 2-D MODIS cloud mask (red circles), by the 1-D CALIOP cloud mask (blue empty circles) and if the distance to clouds detected by the 1-D CALIOP mask are rescaled to estimate the effect of clouds outside the lidar track (blue full circles). The plot extends to $12 \mathrm{~km}$, the 2-D distance that corresponds to a 1-D distance of $20 \mathrm{~km}$ for the blue line in Fig. 4a. The plot is based on the yearlong global dataset, with the number of used lidar profiles decreasing from over 4 million near clouds to just under $30000012 \mathrm{~km}$ away from clouds. Vertically integrated color ratio is calculated as the ratio of vertically integrated backscatters at $532 \mathrm{~nm}$ and $1064 \mathrm{~nm}$.

featuring strong large-scale variability. Finally, we note that the slope in Fig. $4 \mathrm{a}$ is different for the blue line than for the red one because the blue data is also affected by the different sensitivities of MODIS and CALIOP cloud masks.

Figure 5 shows that one can use the blue linear fit in Fig. $4 \mathrm{a}$ to estimate $d_{2 \mathrm{D}}$ from $d_{1 \mathrm{D}}$, and then to rescale color ratio curves based on 1-D CALIOP cloud masks in order to obtain curves similar to the ones based on 2-D MODIS cloud masks. This can be especially helpful for considering the impact of clouds lying outside the lidar track when the MODIS cloud mask has large uncertainties in detecting low clouds, for example at night or over bright surfaces such as snow and ice. In essence, Fig. 5 shows that we can rescale results based on the 1-D CALIOP cloud mask to statistically account for clouds lying off the CALIOP track. We note that the rescaling parameters vary with cloud type.

Regardless of which cloud mask one uses, the typical distance to the nearest cloud can also be of interest because it can help putting into context the importance of near-cloud changes in aerosol particles. For example, larger (smaller) typical distances would imply that nearcloud changes have weaker (stronger) impacts on overall
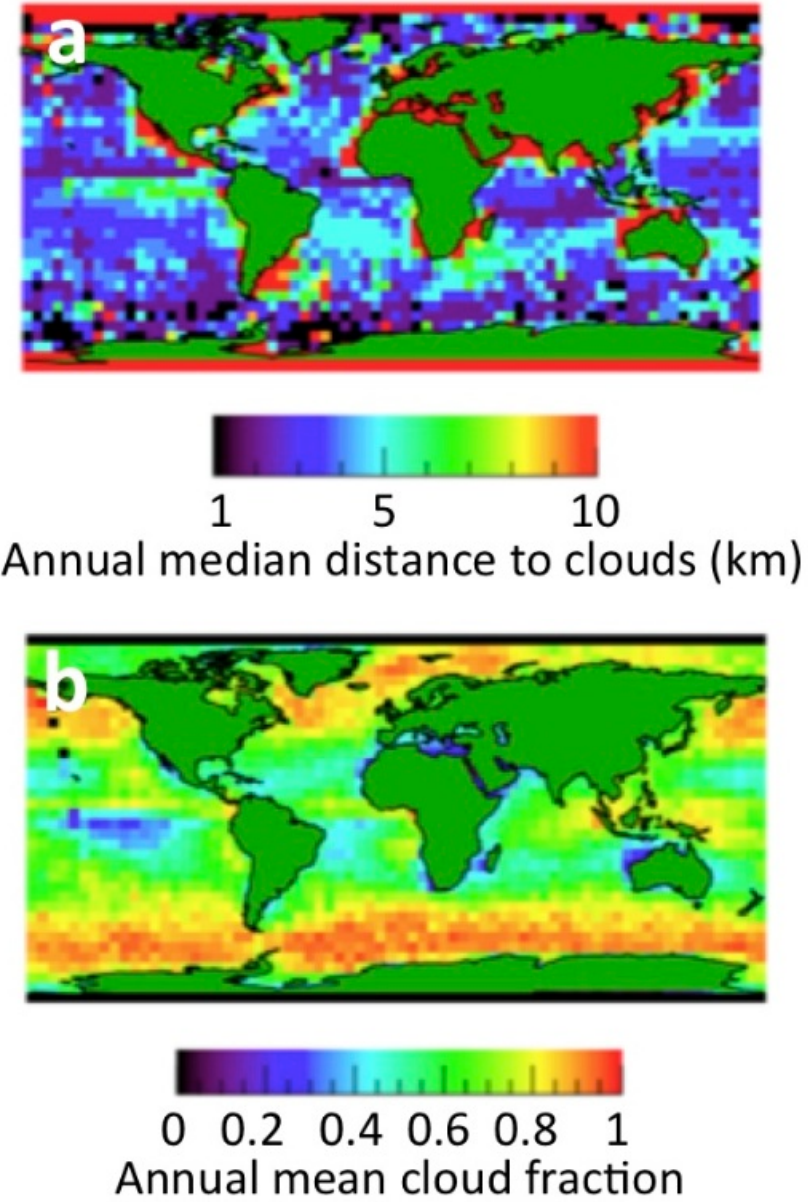

Fig. 6. (a) Annual median distance to low clouds; (b) cloud fraction of low clouds. Both panels are based on the $1 \mathrm{~km}$-resolution MODIS cloud mask and the MODIS cloud top pressure product (with low cloud top pressure exceeding $700 \mathrm{hPa}$ ). Panel (a) uses a 2-D search to determine the distance to clouds. Panel (b) considers as cloud (clear) the MODIS cloud mask values "probably cloud" and "confident cloud" ("probably clear and confident clear").

clear-sky characteristics. Figure 6a shows that this distance varies significantly with location. The variations are caused by two main factors. First, the distance tends to decrease as cloud coverage increases and clouds "grow closer together". A comparison of Fig. $6 \mathrm{a}$ and $\mathrm{b}$ can indeed reveal strong anticorrelations between cloud coverage and distance to clouds, for example the large median distance to clouds over the Mediterranean can be attributed to the small cloud coverage. Second, the typical distance to clouds also depends on cloud type, for example it is lower in the small gaps in cumulus fields than in the vast areas separating large stratiform cloud decks. The effect of cloud type can be illustrated through the two sample areas in Fig. 4c: although cloud coverage is similar in the two areas ( 0.54 and 0.53 , respectively), typical distances to cloud are much smaller in the area on the right (median distance to clouds is $2.2 \mathrm{~km}$ and $1 \mathrm{~km}$ in the 
Table 1. Mid-latitude summer and winter median distances to clouds and, in parentheses, cloud fractions for low clouds based on the MODIS cloud mask. Winter and summer data are based of the 1 December-28 February or 1 June-31 August periods, depending on the hemisphere.

\begin{tabular}{ccc}
\hline & Summer & Winter \\
\hline $30^{\circ}-60^{\circ}$ North & $7.7 \mathrm{~km}(0.39)$ & $3.3 \mathrm{~km}(0.52)$ \\
$30^{\circ}-60^{\circ}$ South & $4.8 \mathrm{~km}(0.61)$ & $2.2 \mathrm{~km}(0.55)$ \\
\hline
\end{tabular}

left and right side areas, respectively). The dominance of marine stratus and stratocumulus can explain, for example, the large median distance to clouds off the coast of California in Fig. 6a.

The typical distance often also varies with season and tends to be greater in summer than in winter. We note that winter and summer calculations use data from the 1 December-28 February or 1 June-31 August periods, depending on the hemisphere. Table 1 shows that at Northern Hemisphere mid-latitudes, the distance being smaller in winter than summer coincides with cloud coverage being larger in winter than summer - a trend consistent with the distance decreasing as clouds "grow nearer". However, Table 1 also shows that at Southern Hemisphere mid-latitudes, the distance being smaller in winter than summer coincides with cloud fractions also being smaller in winter than summer which further illustrates that in addition to cloud fraction, cloud type also greatly impacts the typical distance to clouds. Overall, the annual median distance to clouds over all icefree oceans is around $4.3 \mathrm{~km}$ using the 2-D MODIS cloud mask and $5 \mathrm{~km}$ using the 1-D CALIOP cloud mask. In other words, roughly $50 \%$ of all clear pixels are closer than $5 \mathrm{~km}$ to low clouds (see Fig. 1 in Várnai and Marshak, 2011). Therefore it seems attractive for future studies to characterize nearcloud enhancements by comparing the roughly two halves of clear pixels that are closer or farther than $\sim 5 \mathrm{~km}$ to the nearest cloud, respectively.

\section{Summary}

The purpose of this paper is to help synergistic studies to use data from different satellites for gaining new insights into two critical yet poorly understood aspects of anthropogenic climate change, aerosol-cloud interactions and aerosol radiative effects. For this, the paper examines how cloud information from the MODIS imager can refine our CALIOP lidarbased perceptions of systematic aerosol changes near clouds.

The paper explores this topic by analyzing a yearlong global dataset that covers all ice-free oceans, and includes co-located data by the Aqua satellite's MODIS imager and by the CALIPSO satellite's CALIOP lidar and WFC imager. A statistical analysis of this dataset reveals that, despite some challenges, MODIS's multispectral imaging ability can greatly help the interpretation of CALIOP observations, especially by detecting clouds outside the single line that is observed by the CALIOP lidar along the satellite orbit. Specifically, the main findings are as follows.

Generally, MODIS and WFC reflectances are very similar, with WFC being slightly brighter in dark areas and slightly darker in bright areas. The discrepancies likely come from MODIS viewing obliquely the areas that CALIPSO observes vertically, although calibration issues may also play a role. The local standard deviations in $3 \mathrm{~km}$ by $3 \mathrm{~km}$ areas are somewhat larger for WFC than for MODIS, most likely because a wider instantaneous field-of-view smoothens smallscale variability for WFC. Matching the spatial patterns of MODIS and WFC images reveals that although clouds certainly drift with the wind during the $72 \mathrm{~s}$ between Aqua and CALIPSO overpasses, ignoring this typically modest drift does not significantly alter the observed systematic aerosol changes near low clouds.

By detecting clouds outside the CALIOP track, MODIS reveals that clouds are usually closer to clear areas than CALIOP data would suggest. While this does not change qualitatively our perceptions of aerosol behaviors near clouds, it does impact quantitative features such as median backscatter values at given distances to clouds. The paper finds simple statistical relationships between the distances to cloud in MODIS and CALIOP clear sky data, and shows that this relationship is determined predominantly by cloud spatial autocorrelations. Based on this finding the paper proposes a rescaling approach that statistically accounts for the impact of clouds outside the CALIOP track even when MODIS cannot reliably detect low clouds, for example at night or over ice.

Finally, the paper examines clear areas' typical distance to clouds, as this can help putting into context the importance of near-cloud changes. The results show that the this distance depends on both cloud coverage and cloud type and, as a result, varies both with geographical location and season. Globally, the median distance to clouds in maritime clear areas is in the $4-5 \mathrm{~km}$ range; in other words, about $50 \%$ of all clear pixels are closer than $5 \mathrm{~km}$ to low clouds. This indicates that the pronounced near-cloud changes have significant implications for overall clear-sky characteristics.

In conclusion, the results presented here can help future satellite studies of aerosols near clouds. We plan to report on such a follow-up study - examining relationships between near-cloud changes in MODIS solar reflectances, CALIOP lidar returns, and aerosol and cloud properties retrieved by MODIS and CALIOP - in a future article.

Acknowledgements. We gratefully acknowledge support for this research by the NASA Radiation Sciences Program managed by Hal Maring and by the NASA CALIPSO project supervised by Charles Trepte as the technical officer.

Edited by: A. Kokhanovsky 


\section{References}

Ackerman, S. A., Strabala, K. I., Menzel, W. P., Frey, R. A., Moeller, C. C., and Gumley, L. E.: Discriminating clear sky from clouds with MODIS, J. Geophys. Res., 103, 32141-32157, doi:10.1029/1998JD200032, 1998.

Bar-Or, R. Z., Altaratz, O., and Koren, I.: Global analysis of cloud field coverage and radiative properties, using morphological methods and MODIS observations, Atmos. Chem. Phys., 11, 191-200, doi:10.5194/acp-11-191-2011, 2011.

Barker, H. W. and Davies, J. A.: Solar radiative fluxes for stochastic, scale- invariant broken cloud fields, J. Atmos. Sci., 49, 11151126, 1992.

Charlson, R. J., Ackerman, A. S., Bender, F. A.-M., Anderson, T. L., and Liu, Z.: On the climate forcing consequences of the albedo continuum between cloudy and clear air, Tellus, 59, 715-727, 2007.

Chiu, J. C., Marshak, A., Knyazikhin, Y., Pilewski, P., and Wiscombe, W. J.: Physical interpretation of the spectral radiative signature in the transition zone between cloud-free and cloudy regions, Atmos. Chem. Phys., 9, 1419-1430, doi:10.5194/acp-91419-2009, 2009.

Davis, A. B., Marshak, A., Wiscombe, W. J., and Cahalan, R. F.: Scale invariance of liquid water distributions in marine stratocumulus. Part I: Spectral properties and stationarity issues, J. Atmos. Sci., 53, 1538-1558, 1996.

Eguchi, N. and Yokota, T.: Investigation of clear-sky occurrence rate estimated from CALIOP and MODIS observations, Geophys. Res. Lett., 35, L23816, doi:10.1029/2008GL035897, 2008.

Frey, R. A., Ackerman, S. A., Liu, Y., Strabala, K. I., Zhang, H., Key, J. R., Wang, X.: Cloud Detection with MODIS. Part I: Improvements in the MODIS Cloud Mask for Collection 5, J. Atmos. Ocean. Tech., 25, 1057-1072, 2008.

Jeong, M. J. and Li, Z.: Separating real and apparent effects of cloud, humidity, and dynamics on aerosol optical thickness near cloud edges, J. Geophys. Res., 115, D00K32, doi:10.1029/2009JD013547, 2010.

Kerkweg, A., Wurzler, S., Reisin, T., and Bott, A.: On the cloud processing of aerosol particles: An entraining air-parcel model with two-dimensional spectral cloud microphysics and a new formulation of the collection kernel, Q. J. Roy. Meteor. Soc., 129, 1-18, 2003.

Koren, I., Remer, L. A., Kaufman, Y. J., Rudich, Y., and Martins, J. V.: On the twilight zone between clouds and aerosols, Geophys. Res. Lett., 34, L08805, doi:10.1029/2007GL029253, 2007.

Koren, I., Oreopoulos, L., Feingold, G., Remer, L. A., and Altaratz, O.: How small is a small cloud?, Atmos. Chem. Phys., 8, 38553864, doi:10.5194/acp-8-3855-2008, 2008.

Koren, I., Feingold, G., Jiang, H., and Altaratz, O.: Aerosol effects on the inter-cloud region of a small cumulus cloud field, Geophys. Res. Lett., 36, L14805, doi:10.1029/2009GL037424, 2009.

Liu, Z., Vaughan, M., Winker, D., Kittaka, C., Getzewich, B., Kuehn, R., Omar, A., Powell, K., Trepte, C., and Hostetler, C.: The CALIPSO lidar cloud and aerosol discrimination: Version 2 algorithm and initial assessment of performance, J. Atmos. Ocean. Tech., 26, 1198-1213, doi:10.1175/2009JTECHA1229.1, 2009.
Loeb, N. G. and Schuster, G. L.: An observational study of the relationship between cloud, aerosol and meteorology in broken low-level cloud conditions, J. Geophys. Res., 113, D14214, doi:10.1029/2007JD009763, 2008.

Menzel, W. P., Frey, R. A., Zhang, H., Wylie, D. P., Moeller, C. C., Holz, R. E., Maddux, B., Baum, B. A., Strabala, K. I., and Gumley, L. E.: MODIS Global Cloud-Top Pressure and Amount Estimation: Algorithm Description and Results, J. Appl. Meteorol. Clim., 47, 1175-1198, doi:10.1175/2007JAMC1705.1, 2008.

Redemann, J., Zhang, Q., Russell, P. B., Livingston, J. M., and Remer, L. A.: Case Studies of Aerosol Remote Sensing in the Vicinity of Clouds, J. Geophys. Res., 114, D06209, doi:10.1029/2008JD010774, 2009.

Su, W., Schuster, G. L., Loeb, N. G., Rogers, R. R., Ferrare, R. A., Hostetler, C. A., Hair, J. W., and Obland, M. D.: Aerosol and cloud interaction observed from high spectral resolution lidar data, J. Geophys. Res., 113, D24202, doi:10.1029/2008JD010588, 2008.

Tackett, J. L. and Di Girolamo, L.: Enhanced aerosol backscatter adjacent to tropical trade wind clouds revealed by satellite-based lidar, Geophys. Res. Lett., 36, L14804, doi:10.1029/2009GL039264, 2009.

Twohy, C. H., Coakley Jr., J. A., and Tahnk, W. R.: Effect of changes in relative humidity on aerosol scattering near clouds, J. Geophys. Res., 114, D05205, doi:10.1029/2008JD010991, 2009.

Várnai, T. and Marshak, A.: Global CALIPSO observations of aerosol changes near clouds, IEEE Geosci. Remote S., 8, 19-23, 2011.

Vaughan, M. A., Powell, K. A., Winker, D. M., Hostetler, C. A., Kuehn, R. E., Hunt, W. H., Getzewich, B. J., Young, S. A., Liu, Z., and McGill, M. J.: Fully Automated Detection of Cloud and Aerosol Layers in the CALIPSO Lidar Measurements, J. Atmos. Ocean. Tech., 26, 2034-2050, doi:10.1175/2009JTECHA1228.1, 2009.

Winker, D. M., Vaughan, M. A., Omar, A., Hu, Y., Powell, K. A., Liu, Z., Hunt, W. H., and Young, S. A.: Overview of the CALIPSO mission and CALIOP data processing algorithms, J. Atmos. Ocean. Tech., 26, 2310-2323, doi:10.1175/2009JTECHA1281.1, 2009.

Xue, H., Feingold, G., and Stevens, B.: Aerosol effects on clouds, precipitation, and the organization of shallow cumulus convection, J. Atmos. Sci., 65, 392-406, doi:10.1175/2007JAS2428.1, 2008.

Yang, W., Marshak, A., Várnai, T., and Liu, Z.: Effect of CALIPSO cloud aerosol discrimination (CAD) confidence levels on observations of aerosol properties near clouds, Atmos. Res., in review, 2012. 